\title{
Desempenho e perfil sérico bioquímico de frangos de corte alimentados com rações contendo produtos homeopáticos
}

\author{
Perfomance and serum biochemical levels of broillers fed diets containing homeopathic \\ products
}
SANTOS, Fabiana Ramos ${ }^{1 *}$; SANTANA, Raquel Oliveira ${ }^{1}$; CARVALHO, Elaine de Assis ${ }^{1}$; COSTA, Natália Alves ${ }^{1}$; MINAFRA, Cibele Silva ${ }^{1}$; OLIVEIRA, Paula Rodrigues ${ }^{1}$

\author{
${ }^{1}$ Instituto Federal Goiano, Departamento de Zootecnia, Rio Verde, Goiás, Brasil \\ *Endereço para correspondência: fabiana.santos@ifgoiano.edu.br
}

\section{RESUMO}

O estudo foi realizado com o objetivo de avaliar o efeito da inclusão de produtos homeopáticos sobre o desempenho e perfil bioquímico sérico de frangos de corte. $\mathrm{O}$ delineamento experimental utilizado foi inteiramente casualizado com quatro tratamentos e oito repetições de 20 aves cada, totalizando 640 pintos de corte, machos. Os tratamentos avaliados foram: Controle (dieta sem inclusão de produtos homeopáticos), Fator Pró aves $^{\circledR}$ (FP) (fornecido do $1^{\circ}$ aos $42^{\circ}$ dias de idade), Fator Estresse aves ${ }^{\circledR}$ (FE) (fornecido até os 14 dias de vida das aves), Fator Estresse aves ${ }^{\circledR}$ + Fator Pró aves ${ }^{\circledR}$ (FE+FP) (FE fornecido até os 14 dias de idade, associado ao fornecimento do FP do $15^{\circ}$ aos $42^{\circ}$ dias de idade). Os resultados foram submetidos à análise de variância e as médias comparadas pelo teste de Tukey a 5\%. A inclusão dos fatores homeopáticos aumentou $\mathrm{o}$ peso médio e ganho de peso das aves aos 21dias de idade. Aos 42 dias, foram determinados maior índice de eficiência produtiva e viabilidade (\%) para aves consumindo ração com a adição do FP e FE, respectivamente. Não houve diferenças estatísticas entre os parâmetros séricos bioquímicos: proteína total, colesterol, fosfatase alcalina e as transaminases GOT e GPT, entretanto, ocorreu uma diminuição dos níveis de colesterol para as aves alimentadas com a ração contendo o FP. Conclui-se que os produtos homeopáticos não afetam o desempenho das aves aos 42 dias de idade, porém, melhoram o rendimento de carcaça, o índice de eficiência produtiva, a viabilidade e reduzem os níveis de colesterol sérico.

Palavras-chave: aves de corte, bioquímica, desempenho, homeopatia, soro

\section{SUMARRY}

The study was conducted to evaluate the effect of adding homeopathic products on performance and serum biochemical profile of broilers. The experimental design was completely randomized design with four treatments and eight repetitions of 20 birds each, a total of 640 broiler, males. The trataments avalied was: Control (diet without incluision of homeopathic factors), Factor Pro birds ${ }^{\circledR}$ (FP) (supplied from the 1 st to 42 days old), Factor Stress birds ${ }^{\circledR}$ (FE) (provided until 14 days of life for birds), Factor Stress birds ${ }^{\circledR}+$ Factor Pro birds ${ }^{\circledR}$ (FS + FP) (FE supplied until 14 days of age, with the supply of the FP 15 to 42 days of age). The results were subjected to analysis of variance and means were compared by Tukey test at 5\%. The inclusion of homeopathics products increased the mean weight and weight gain of birds to 21 days of age. At 42 days, were determined greater productive efficiency and viability (\%) for broilers consuming diets with the addition of $\mathrm{PF}$ and EF, respectively. There were no statistical differences between the serum biochemical parameters total protein, cholesterol, alkaline phosphatase, and transaminases GOT and GPT, however, there was a decrease in cholesterol levels for broilers fed diet containing FP. It is concluded that homeopathic factors do not affect the performance of broilers at 42 days of age, however, improve the carcass yield, productive efficiency, viability and reduce serum cholesterol levels.

Keywords: broilers, biochemistry, performance, homeopathy, serum 


\section{INTRODUÇ̃̃̃O}

Para se obter elevados índices de produtividade na avicultura industrial utiliza-se elevada densidade de criação, modernas técnicas de produção e faz-se necessário a inclusão na ração de antibióticos com a finalidade promotora de crescimento. Entretanto, existe uma preocupação crescente com o uso intensivo de antimicrobianos pela possibilidade destes deixarem resíduos em produtos de origem animal (LEITE et al., 2012).

Assim, a aplicação da homeopatia na produção de frangos pode ser uma prática viável, uma vez que é uma terapêutica de fácil administração, com custo reduzido, com efeitos positivos sobre o desenvolvimento e não deixa resíduos tóxicos na carne (AMARAL, 2004).

Resultados positivos de desempenho de frangos com a utilização de medicamentos homeopáticos com diferentes princípios ativos foram observados por Briones (1987) e Vizzani \& Novelli (1992). Também, Oba et al. (2006) avaliaram a inclusão de Hypericum perforatum para o tratamento de estresse em frangas de reposição e observaram que as aves tratadas eram mais calmas e apresentaram melhor conversão alimentar. Por outro lado, Boratto et al. (2004) verificaram que a homeopatia não melhorou aos 42 dias de idade, o desempenho de frangos inoculados com Escherichia coli. Da mesma forma, Chaves et al. (2006) constataram que a utilização da Thuja occidentalis não regrediu as lesões de pele das aves infectadas com poxvírus aviários.

Os produtos homeopáticos Fator estresse ${ }^{\odot}$ e Fator pró digestão aves ${ }^{\complement}$ são indicados para o controle do estresse e incremento no aproveitamento nutricional, respectivamente. Entretanto, são raros trabalhos com rigor científico que comprovem a eficiência destes e demais medicamentos homeopáticos na produção de frangos de corte.

Além disso, os resultados de pesquisas obtidos ainda são contraditórios e demostram a necessidade da revisão dos métodos utilizados na abordagem da terapêutica homeopática zootécnica (CHABEL et al., 2009).

Dessa forma, devem ser realizados novos ensaios verificando além do desempenho, a possibilidade destas substâncias causarem intoxicações ou alterações no metabolismo normal das aves. Neste contexto, as análises séricas bioquímicas podem constituir-se em indicativos da atuação dos princípios homeopáticos no organismo dos frangos.

Diante do exposto, objetivou-se, com este trabalho avaliar o desempenho, o rendimento de carcaça, de cortes e perfil sérico bioquímico de frangos alimentados com rações contendo produtos homeopáticos.

\section{MATERIAL E MÉTODOS}

O ensaio foi conduzido no aviário experimental do Instituto Federal Goiano - Câmpus Rio Verde. As variáveis séricas bioquímicas foram realizados no Laboratório de Bioquímica e Metabolismo Animal do referido Instituto.

Foram utilizados 640 pintos de um dia da linhagem $\mathrm{Cobb}^{\circledR}$, com peso médio inicial de 40,0 $\pm 2,0$ gramas. As aves foram alojadas em 32 boxes de $2 \mathrm{~m}^{2}$ cada, com bebedouros tipo nipple, um comedouro tubular e uma fonte de aquecimento com lâmpadas de 100 watts. Capim Napier seco e picado a uma altura de $10 \mathrm{~cm}$ do solo foi utilizado 
como cama de aviário.

Todas as aves foram alimentadas com ração comercial específica para cada fase de criação do animal, compreendida entre fase inicial (1 a 21 dias de idade), crescimento ( 22 a 35 dias de idade) e final (36 a 42 dias de idade).

Os animais foram distribuídos em delineamento inteiramente casualizado, com quatro tratamentos e oito repetições, com 20 aves cada. Os tratamentos estudados foram: Controle (C), ração sem adição de produtos homeopáticos; Fator Estresse aves (FE) fornecido até os 14 dias de vida das aves; Fator Estresse aves + Fator Pró digestão aves $(\mathrm{FE}+\mathrm{FP})$, as aves foram alimentadas com o fator estresse aves até os 14 dias de idade e a partir daí o fator pró digestão aves foi incluído na alimentação e; Fator Pró digestão aves (FP) fornecido ás aves do $1^{\circ}$ aos $42^{\circ}$ dias de idade.

Os produtos homeopáticos foram administrados via oral na dose de $0,05 \mathrm{~g} /$ ave/dia por meio da mistura "on top" na ração comercial. O Fator Estresse Aves ${ }^{\circledR}$ é composto por
Chamomilla CH 12, Bixa orellana 0,75 g, Sacarose q.s.p. 100g. Enquanto que o fator Fator Pró Digestão Aves ${ }^{\circledR}$ apresenta Soja CH12; Milho CH12; Vitamina CH12; Bixa orellana $0,75 \mathrm{~g}$; Sacarose q.s.p. 100g. Ressalta-se que cada $\mathrm{CH}$ representa o Centesimal Hahnemanianno, ou seja, a diluição do composto em escala 1:100. Todos os fatores pertencem a marca comercial Arenales, Homeopatia Animal.

Os produtos testados foram misturados semanalmente na ração. Para melhorar a dispersão dos mesmos, a quantidade preconizada de produto em cada tratamento foi cuidadosamente homogeneizada em um quilograma de ração e posteriormente adicionada na quantidade total a ser consumida na semana. A mistura total (produtos homeopáticos e ração) foi realizada em misturador automático de rações com capacidade de $500 \mathrm{~kg}$.

Na tabela 1 são apresentados os níveis dos nutrientes e a composição básica das rações comerciais utilizadas para a fase inicial ( 1 a 21 dias de idade) e crescimento ( 22 a 35 dias de idade) e final ( 36 a 42 dias de idade).

Tabela 1. Composição básica e níveis da garantia das rações comerciais ${ }^{1}$ utilizadas para fase inicial ( 1 a 21 dias de idade), crescimento (22 a 35 dias) e final (36 a 42 dias de idade)

\begin{tabular}{lccc}
\hline Níveis Nutricionais (\%) & Fase Inicial & Fase Crescimento & Fase Final \\
\hline Umidade (Máx.) & 12,00 & 12,00 & 12,00 \\
Proténa Bruta (Mín.) & 21,00 & 20,00 & 18,00 \\
Extrato Etéreo (Mín.) & 3,00 & 2,50 & 2,50 \\
Matéria Fibrosa (Máx.) & 6,00 & 6,00 & 7,00 \\
Matéria Mineral (Máx.) & 8,00 & 8,00 & 8,00 \\
Cálcio (Máx.) & 1,30 & 1,30 & 1,30 \\
Fósforo (Mín.) & 0,48 & 0,47 & 0,45 \\
\hline
\end{tabular}

${ }^{\mathrm{T}}$ Cooperativa Mista dos Produtores Rurais do Sudoeste Goiano Ltda. (COMIGO).

Foram analisadas as seguintes variáveis de desempenho: peso médio das aves (PM), ganho de peso (GP), consumo de ração $(\mathrm{CR})$, conversão alimentar $(\mathrm{CA})$, eficiência alimentar (EA) aos 21 e 42 dias de idade. Ao final do ensaio (42 
dias de idade) foram calculadas a viabilidade (\%), índice de eficiência produtiva (IEP) e as características de carcaça: rendimento de carcaça (RC), rendimento de coxa $(\mathrm{RCx})$, rendimento de sobrecoxa (RScx) e rendimento de peito (RP) após o abate.

Para avaliar o PM, CR, CA e EA, todas as aves e as rações (fornecimento $\mathrm{e}$ sobras) foram pesadas no $1^{\circ}, 21^{\circ}$ e $42^{\circ}$ dias de idade. A viabilidade foi calculada corrigindo-se o percentual total de aves pelo índice de mortalidade (100 - \% de mortalidade).

O IEP é uma variável indireta usada para avaliar o desempenho do lote. Esse índice foi determinado de acordo com a fórmula: IEP $=[($ peso vivo $* \%$ de viabilidade) / (Idade de abate em dias * conversão alimentar)] $* 100$.

Para determinação do rendimento de carcaça e cortes nobres, foram selecionadas duas aves por parcela experimental (dentro do peso médio da parcela) e estas foram submetidas a jejum de ração de 8 horas. Após o jejum as aves foram pesadas, abatidas $\mathrm{e}$ evisceradas. A carcaça quente (sem os pés e cabeça) foi pesada novamente para o cálculo do rendimento percentual de carcaça. Para a determinação do rendimento percentual de cortes nobres, as carcaças foram cortadas e separados o peito, coxas e sobrecoxas para pesagem, sendo o percentual de partes determinado em relação ao peso da carcaça.

Aos 21 e 42 dias no período da manhã, foi coletado $3 \mathrm{~mL}$ de sangue pela veia ulnar de oito aves por tratamento, sendo uma ave de cada repetição. As aves foram selecionadas de forma aleatória e submetidas a jejum prévio de 12 horas.

$\mathrm{O}$ sangue coletado foi armazenado em tubos identificados, centrifugado a $6.000 \mathrm{rpm}$ por 15 minutos, para obtenção do soro, do qual procederamse as análises, todas em triplicata.
Foram realizadas análises dos parâmetros séricos bioquímicos: cálcio $(\mathrm{Ca})$ e fósforo $(\mathrm{P})$, da proteína total (PT), colesterol (COL) e das enzimas fosfatase alcalina (FA), glutamato oxaloacetato transaminase (GOT) e glutamato piruvato transaminase (GPT). Todas as análises foram realizadas por kits comerciais da LABTEST $^{\circledR}$. Os princípios para determinação de cada parâmetro bioquímico (cálcio, fósforo, proteína total, colesterol, fosfatase alcalina e transaminase) foram determinados pelos referidos kits (LABTEST, 2013).

$\mathrm{O}$ cálcio foi determinado colorimetricamente através de um complexo corado com cresolftaleína em meio alcalino. $\mathrm{O}$ fósforo inorgânico reage com molibdato em meio ácido, formando um complexo fosfomolibdato. A adição de uma solução alcalina permite que esse complexo seja reduzido pelo ácido ascórbico, dando origem a um novo complexo fosfomolibdato de cor azul. Paralelamente, as proteínas anteriormente precipitadas se dissolvem.

$\mathrm{Na}$ análise da proteína total, o reagente do biureto, uma solução de sulfato de cobre, citrato trissódico, carbonato de sódio e hidróxido de sódio, reage com as proteínas da amostra, formando um complexo corado de cor violeta, que é proporcional à concentração protéica da amostra.

O colesterol no soro é quantificado através das seguintes reações enzimáticas: ésteres de colesterol reagem com a água e liberam colesterol livre e ácidos graxos, o colesterol livre na presença de oxigênio libera colesterona mais peróxido de hidrogênio, que juntamente com a 4 aminoantipirina + Fenol formam a 4antipirilquinonimina mais água. $\mathrm{O}$ produto formado pela oxidação da 4aminoantipirina (4-antipirilquinonimina) é avermelhada e sua intensidade 
diretamente proporcional à concentração de colesterol no soro.

Para a análise de fosfatase o soro é incubado com p-Nitrofenilfosfato, sal ciclohexilamina (substrato). Sob ação das fosfatases, dá-se a hidrólise do sal com a liberação de p-Nitrofenol. Com adição de soda à reação e alcalinização do meio, o p-Nitrofenol liberado tornase amarelo. A atividade de fosfatase é proporcional à quantidade de $p$ Nitrofenol neo-formado.

As transaminases são enzimas que catalisam a transferência de grupamentos amina e alfa aminoácidos para alfa acetoácidos: a L-alanina e o cetoglutarato reagem dando origem ao glutamato $\mathrm{e}$ piruvato através da ação enzimática da glutamato piruvato transaminase (GPT). $\mathrm{O}$ L- aspartato e o cetoglutarato reagem pela ação da glutamato oxaloacetato transaminase (GOT), liberando glutamato e oxaloacetato.

$\mathrm{O}$ piruvato e o oxaloacetato formados são proporcionais à atividade enzimática e medidos através da formação de suas hidrazonas, intensamente coradas, em meio alcalino. As análises estatísticas das variáveis avaliadas foram realizadas com utilização do programa SAEG (UFV, 2007). Os resultados foram submetidos à análise de variância utilizando o teste de Tukey para comparação de médias entre os tratamentos $(p<0,05)$.

\section{RESULTADOS E DISCUSSÃO}

Aos 21 dias de idade, não foi verificado o efeito significativo para $\mathrm{CR}, \mathrm{CA}$ e $\mathrm{EA}$ das aves, entretanto, o PM e o GP foram significativamente maiores para os tratamentos FE + FP e FP (Tabela 2). As aves alimentadas com rações contendo FE apresentaram PM e GP intermediários, enquanto o grupo $\mathrm{C}$ obteve os menores valores.

Resultados semelhantes a este foram observados por Boratto et al. (2004) que também não encontraram diferenças para o CR das aves no período de 1 a 21 dias alimentadas com rações contendo antibiótico, probiótico e homeopatia, sendo este último um nosódio de E.coli com dinamização CH 30.

Embora sem efeitos na CA, com a adição na ração dos $\mathrm{FE}+\mathrm{FP}$ e $\mathrm{FP}$ verificou-se uma elevação de aproximadamente 3,9\% no GP das aves aos 21 dias de idade. Este resultado demonstra uma clara tendência dos fatores homeopáticos em melhorar $\mathrm{o}$ desempenho dos frangos de corte na fase inicial, sendo esta, uma das mais estressantes fisiologicamente ao animal. De acordo com Arenales (2003), a homeopatia promove aves mais resistentes e sadias, contribui para o melhor aproveitamento dos alimentos e amplia dessa forma o desempenho animal. Portanto, esta pequena diferença estatística, pode ser um fator positivo para a melhoria na lucratividade em escala, uma vez que na avicultura industrial, pequenos ganhos em produtividade por ave, podem refletir na remuneração final.

Porém, aos 42 dias de idade das aves, os diferentes tratamentos não influenciaram os índices produtivos avaliados (Tabela 2). Semelhante ao observado neste ensaio Boratto et al. (2004) trabalharam com a inclusão de antibiótico, de probiótico e de homeopatia em frangos de corte inoculados ou não com Escherichia coli e verificaram efeito positivo dos aditivos na fase inicial (até 21 dias). Porém, os autores também observaram que aos 42 dias, o desempenho das aves não foi alterado pelos tratamentos. Os resultados obtidos aos 42 dias de idade das aves também corroboram com os observados por Hadipour et al. (2011), 
que verificaram que o fornecimento de medicamento homeopático a base de Calcarea carbonica, Calcarea phosphorica, Hypericum perforatum e Sulphur em solução hidro alcóolica a $5 \%$, também não proporcionaram efeitos significativos sobre o GP, CA e mortalidade de frangos de corte aos 42 dias de idade.

É possível que os fatores homeopáticos na dosagem utilizada não foram suficientes para produzir efeitos benéficos sobre o desempenho dos animais em idade mais avançada de desenvolvimento. Entretanto, são escassos os trabalhos com homeopatia na produção de aves e, portanto, tornase difícil comparar os resultados de estudos científicos conduzidos com esta terapêutica, uma vez que cada trabalho utiliza determinado tipo de fator, com diferentes dosagens, formas de administração e condições experimentais distintas.

Tabela 2. Desempenho de frangos de corte no período de 1 a 21 dias alimentados com rações contendo fatores homeopáticos

\begin{tabular}{lccccc}
\hline Tratamento & PM $(\mathrm{g})$ & GP $(\mathrm{g})$ & CR $(\mathrm{g})$ & CA $(\mathrm{g}: \mathrm{g})$ & EA(g:g) \\
\hline \multicolumn{5}{c}{$1 \mathrm{a} 21$ dias de idade } \\
\hline C & $750,69^{\mathrm{b}}$ & $707,31^{\mathrm{b}}$ & $1097,56^{\mathrm{a}}$ & $1,55^{\mathrm{a}}$ & $0,64^{\mathrm{a}}$ \\
FE & $763,87^{\mathrm{ab}}$ & $721,00^{\mathrm{ab}}$ & $1148,75^{\mathrm{a}}$ & $1,56^{\mathrm{a}}$ & $0,64^{\mathrm{a}}$ \\
FE+FP & $780,07^{\mathrm{a}}$ & $736,81^{\mathrm{a}}$ & $1150,65^{\mathrm{a}}$ & $1,58^{\mathrm{a}}$ & $0,64^{\mathrm{a}}$ \\
FP & $780,32^{\mathrm{a}}$ & $737,00^{\mathrm{a}}$ & $1160,41^{\mathrm{a}}$ & $1,58^{\mathrm{a}}$ & $0,65^{\mathrm{a}}$ \\
\hline Valor de P & 0,0393 & 0,0350 & 0,4341 & 0,2341 & 0,3124 \\
CV (\%) & 2,58 & 2,97 & 3,95 & 4,05 & 4,12 \\
\hline \multicolumn{5}{c}{22 a 42 dias de idade } \\
\hline C & 2,40 & 1,65 & 3,51 & 2,12 & 0,47 \\
FE & 2,44 & 1,67 & 3,54 & 2,11 & 0,47 \\
FE+FP & 2,44 & 1,66 & 3,51 & 2,11 & 0,47 \\
FP & 2,46 & 1,68 & 3,50 & 2,08 & 0,48 \\
\hline Valor de P & 0,0895 & 0,2543 & 0,4142 & 0,2281 & 0,5587 \\
CV (\%) & 3,85 & 4,13 & 4,54 & 3,70 & 3,64 \\
\hline C $=$
\end{tabular}

$\mathrm{C}=$ ração controle; $\mathrm{FE}=$ fator estresse; $\mathrm{FE}+\mathrm{FP}=$ fator estresse aves + fator pró aves; $\mathrm{FP}=$ fator pró aves.

*Médias seguidas por letras minúsculas diferentes diferem entre si pelo teste de Tukey a $5 \%$ d probabilidade.

Além disso, é importante ressaltar que os animais utilizados no experimento não sofreram desafio ambiental ou sanitário, fator este que poderia ter intensificado a atuação dos fatores homeopáticos utilizados, já que uma das funções dos mesmos é controlar os efeitos adversos gerados pelo estresse.

Maior viabilidade de criação foi observada nas aves que receberam ração contendo $\mathrm{FE}$, enquanto a $\mathrm{C}$ e a $\mathrm{FP}$ apresentaram valores de viabilidade medianos (Tabela 3). Os resultados obtidos demonstram que a associação dos fatores homeopáticos $(\mathrm{FE}+\mathrm{FP})$ não foi eficiente em reduzir a mortalidade das aves, indicando que esta forma de administração precisa ser melhor investigada.

Toledo et al. (2007) trabalharam com dietas para frangos de corte contendo antibiótico e/ou fitoterápico como promotores, adicionados isoladamente ou associados e, diferente do que foi observado neste trabalho, verificaram que houve maior mortalidade para $\mathrm{o}$ 
tratamento controle que não recebeu nenhum aditivo químico ou natural.

Ressalta-se, que de uma forma geral observou-se neste ensaio baixos índices de mortalidade para as aves tratadas ou não com fatores homeopáticos. É possível que a ausência de desafio sanitário e as boas condições de manejo sejam as principais causas da reduzida taxa de mortalidade neste ensaio. Não foi constatada durante $\mathrm{o}$ período experimental nenhuma morte nas aves alimentadas com o FE, atestando a eficiência deste fator em reduzir o estresse das aves e contribuir para uma maior taxa sobrevivência. O IEP foi maior para o grupo $\mathrm{FP}$, enquanto os tratamentos $\mathrm{C}$ e $\mathrm{FE}+\mathrm{FP}$ apresentaram os menores valores (Tabela 3 ).

Tabela 3. Viabilidade e Índice de eficiência produtiva (IEP), de frangos de corte alimentados com rações contendo fatores homeopáticos

\begin{tabular}{lcc}
\hline Tratamento & Viabilidade (\%) & IEP \\
\hline $\mathrm{C}$ & $98,12^{\mathrm{ab}}$ & $298,07^{\mathrm{b}}$ \\
$\mathrm{FE}$ & $100,00^{\mathrm{a}}$ & $308,46^{\mathrm{ab}}$ \\
$\mathrm{FE}+\mathrm{FP}$ & $96,25^{\mathrm{b}}$ & $298,26^{\mathrm{b}}$ \\
$\mathrm{FP}$ & $98,75^{\mathrm{ab}}$ & $310,64^{\mathrm{a}}$ \\
\hline Valor de P & 0,0023 & 0,0467 \\
$\mathrm{CV}(\%)$ & 2,52 & 4,97 \\
\hline $\mathrm{C}=$ ração controle; FE $=$ fator estresse; FE+FP $=$ fator estresse aves + fator pró aves; FP $=$ fator pró aves. \\
*Médias seguidas por letras minúsculas diferentes diferem entre si pelo teste de Tukey a 5\% de \\
probabilidade.
\end{tabular}

O IEP é muito utilizado pela indústria para remunerar seus integrados de acordo com metas pré-estabelecidas. De acordo com cada sexo e idade do lote existe uma meta de produção, que vem aumentando significativamente nos últimos anos devido às melhorias nos mais diferentes segmentos como nutrição, genética, sanidade, manejo, ambiência, entre outros (MORO et al., 2005).

Não foi observado na literatura trabalhos que avaliem o IEP de frangos de corte tratados com homeopatia. Entretanto, semelhante ao encontrado nesta pesquisa, Siena et al. (2010), trabalharam com alevinos juvenis de tilápias do Nilo e concluiram que o uso do núcleo homeopático Homeopatila $100^{\circledR}$ a $40 \mathrm{ml} / \mathrm{kg}$ de ração, contribuiu para uma melhor sobrevivência e consequentemente maior IEP destes animais.

A inclusão dos diferentes fatores homeopáticos influenciou o rendimento de carcaça, sendo o menor valor obtido no tratamento controle. Entretanto o rendimento de coxa, sobrecoxa e peito não sofreram influência dos tratamentos avaliados (Tabela 4).

De acordo com Teixeira et al. (2010), o rendimento de carcaça é uma característica diretamente relacionada à produção de carne e pode variar conforme os fatores intrínsecos (genética, sexo, peso e idade) e/ou extrínsecos (nutrição, ambiente e manejo pré e pós abate) ao animal.

$\mathrm{O}$ incremento médio no rendimento de carcaça das aves pela adição dos fatores homeopáticos foi igual a 5,7\%, valor este superior ao observado em pesquisas com outras espécies de animais. Ribeiro 
et al. (2011) trabalhando com a terminação de novilhos nelores e tabapuãs confinados recebendo dietas contendo produtos homeopáticos Estresse $^{\circledR} \mathrm{e} \mathrm{o}$ Fator Pró Final $^{\circledR}$ ) registraram um acréscimo de 3,4\% no peso vivo final e de $2,5 \%$ no peso de carcaça quente dos animais tratados em relação animais controle sem tratamento. Os autores observaram ainda, que não houve influência dos fatores homeopáticos sobre o rendimento de ossos, sugerindo que o incremento no rendimento de carcaça foi decorrente de uma maior deposição protéica.

Tabela 4. Rendimento de carcaça (RC), rendimento de coxa (RCx), sobrecoxa (RScx) e peito (RP) de frangos de corte alimentados com rações contendo fatores homeopáticos

\begin{tabular}{lcccc}
\hline Tratamento & $\mathrm{RC}(\%)$ & $\mathrm{RCx}(\%)$ & $\mathrm{RScx}(\%)$ & $\mathrm{RP}(\%)$ \\
\hline $\mathrm{C}$ & $71,20^{\mathrm{b}}$ & 14,78 & 13,95 & 27,67 \\
$\mathrm{FE}$ & $75,44^{\mathrm{a}}$ & 14,38 & 14,31 & 29,06 \\
$\mathrm{FE}+\mathrm{FP}$ & $74,98^{\mathrm{a}}$ & 14,05 & 14,22 & 27,49 \\
$\mathrm{FP}$ & $75,32^{\mathrm{a}}$ & 13,16 & 15,24 & 28,56 \\
\hline Valor de P & 0,0458 & 0,3234 & 0,1589 & 0,3397 \\
CV $(\%)$ & 2,35 & 4,64 & 5,71 & 5,04 \\
\hline
\end{tabular}

$\mathrm{C}=$ ração controle; $\mathrm{FE}=$ fator estresse; $\mathrm{FE}+\mathrm{FP}=$ fator estresse aves + fator pró aves; $\mathrm{FP}=$ fator pró aves.

*Médias seguidas por letras minúsculas diferentes diferem entre si pelo teste de Tukey a 5\% de probabilidade.

Aos 21 dias de idade, os níveis de Ca e $\mathrm{P}$ variaram entre os tratamentos estudados. Não houve diferenças estatísticas entre as variáveis bioquímicas PT, COL, FA, GOT e GPT, para aves que receberam os fatores homeopáticos e a dieta controle. Porém, aos 42 dias de idade, os níveis séricos de $\mathrm{Ca}$ diminuíram nas aves do grupo $\mathrm{FE}+\mathrm{FP}$, havendo também um ligeiro aumento dos níveis de PT para as aves alimentadas com FP (Tabela 5).

Embora com variações nos teores de $\mathrm{Ca}$ séricos, observa-se que todos os tratamentos homeopáticos resultaram em relação Ca:P próxima a 2:1 (valores entre 2,06 a 2,23:1). Segundo Minafra et al. (2008) esta relação é considerada ideal em organismos dentro do estado de normalidade.

Além disso, a fosfatase alcalina é uma enzima que aumenta a concentração de fosfato inorgânico ou ativa fibras de colágeno para deposição de sais de cálcio na matriz óssea, portanto, o nível sérico dessa enzima é, em geral, indicador da velocidade de formação óssea (MINAFRA et al., 2008). A ausência de diferenças na concentração de fosfatase alcalina dos animais dos diferentes tratamentos indica não haver influência dos fatores homeopáticos sobre o metabolismo ósseo dos frangos tratados.

Vieites et al. (2004) analisaram o soro sanguíneo de aves de corte alimentadas com diferentes níveis de proteína bruta e de balanço eletrolítico aos 21 dias e encontraram níveis médios de 8,27; 7,095 e 6,28 para $\mathrm{Ca}, \mathrm{P}$ e proteína total, respectivamente, resultados semelhantes aos encontrados neste trabalho para $\mathrm{Ca}$ $(8,94)$ e P $(6,40)$.

A GOT e GPT são transaminases envolvidas no metabolismo de aminoácidos no fígado. A análise da 
Rev. Bras. Saúde Prod. Anim., Salvador, v.15, n.2, p.394-405 abr./jun., 2014 http://www.rbspa.ufba.br ISSN 15199940

concentração destas enzimas no tecido hepático é um recurso bioquímico utilizados para verificar o bom funcionamento do órgão (MINAFRA et al., 2008).

Borsa et al. (2006) e Minafra et al. (2008) verificaram para frangos de corte aos 21 dias de idade valores de GOT entre 202 e 375 (UI/L), portanto, os resultados obtidos para esta transaminase neste ensaio são considerados normais para a espécie.

Tabela 5. Valores séricos médios da concentração de cálcio ( $\mathrm{Ca} \mathrm{mg} / \mathrm{dL})$, fósforo $(\mathrm{Pmmol} / \mathrm{L})$, proteína total $(\mathrm{PT} \mathrm{g} / \mathrm{dL})$, colesterol $(\mathrm{COL} \mathrm{mg} / \mathrm{dL})$, fosfatase alcalina (FA UI/L), glutamato oxaloacetato transaminase (GOT U/L) e glutamato piruvato transaminase (GPT U/L) de frangos de corte aos 21 e 42 dias de idade

\begin{tabular}{|c|c|c|c|c|c|c|c|}
\hline \multirow{2}{*}{ Item } & $\mathrm{Ca}$ & $\mathrm{P}$ & PT & $\mathrm{COL}$ & FA & GOT & GPT \\
\hline & \multicolumn{7}{|c|}{21 dias de idade } \\
\hline $\mathrm{C}$ & $8,75^{\mathrm{b}} \mathrm{c}$ & $6,05^{b}$ & 3,21 & 185,08 & 565,33 & 201,15 & 79,99 \\
\hline FE & $9,44^{\mathrm{a}}$ & $6,42^{\mathrm{ab}}$ & 2,96 & 153,32 & 556,89 & 208,01 & 78,75 \\
\hline $\mathrm{FE}+\mathrm{FP}$ & $8,58^{\mathrm{c}}$ & $7,03^{\mathrm{a}}$ & 2,91 & 170,62 & 567,35 & 211,80 & 78,94 \\
\hline FP & $8,99^{\mathrm{b}}$ & $6,08^{b}$ & 3,20 & 170,32 & 557,34 & 214,44 & 78,81 \\
\hline Valor de $\mathrm{P}$ & 0,0005 & 0,0134 & 0,4245 & 0,5876 & 0,2567 & 0,2998 & 0,1589 \\
\hline \multirow[t]{2}{*}{$\mathrm{CV}(\%)$} & 1,31 & 3,68 & 9,82 & 17,39 & 1,50 & 5,91 & 3,25 \\
\hline & \multicolumn{7}{|c|}{42 dias de idade } \\
\hline $\mathrm{C}$ & $11,05^{\mathrm{a}}$ & 4,13 & $3,38^{\mathrm{ab}}$ & $410,58^{\mathrm{a}}$ & 466,48 & 229,93 & 68,64 \\
\hline $\mathrm{FE}$ & $10,71^{\mathrm{ab}}$ & 4,79 & $3,07 b$ & $398,77^{\mathrm{a}}$ & 483,74 & 232,16 & 68,06 \\
\hline $\mathrm{FE}+\mathrm{FP}$ & $10,63^{\mathrm{b}}$ & 5,15 & $3,51^{\mathrm{ab}}$ & $249,74^{\mathrm{b}}$ & 381,64 & 209,12 & 73,05 \\
\hline $\mathrm{FP}$ & $10,68^{\mathrm{ab}}$ & 5,03 & $3,78^{\mathrm{a}}$ & $220,64^{b}$ & 435,99 & 216,80 & 73,73 \\
\hline Valor de $\mathrm{P}$ & 0,0025 & 0,1354 & 0,0295 & 0,0333 & 0,3231 & 0,3354 & 0,1719 \\
\hline CV $(\%)$ & 1,5 & 11,71 & 5,97 & 11,91 & 15,18 & 7,8 & 3,53 \\
\hline
\end{tabular}

$\mathrm{C}=$ ração controle; $\mathrm{FE}=$ fator estresse; $\mathrm{FE}+\mathrm{FP}=$ fator estresse aves + fator pró aves; $\mathrm{FP}=$ fator pró aves.

* Médias seguidas por letras minúsculas diferentes diferem entre si pelo teste de Tukey a $5 \%$ de probabilidade.

Já para GPT, os resultados observados são superiores aos verificados por Borsa et al. (2006) que determinaram em aves aos 21 dias de idade valores entre $14 \mathrm{e}$ 34 (UI/L). Minafra et al. (2008) trabalhando com níveis de ácido glutâmico e vitamina $\mathrm{k}$ na dieta de frangos encontraram valores de GPT que corroboram com os verificados neste ensaio (61 a $88 \mathrm{UI} / \mathrm{L}$ ). Segundo os autores os valores encontrados mantiveram-se em limites superiores aos considerados normais, o que pode indicar possíveis alterações do fígado e de seu metabolismo nas aves analisadas.
Salienta-se que os níveis de GPT mantiveram-se elevados em todos os tratamentos, portanto, não é possível afirmar que a possível alteração hepática tenha sido causada pela inclusão dos fatores homeopáticos. De acordo com Borsa et al. (2006) as variações nos níveis séricos das diferentes enzimas estudadas em relação aos resultados encontrados por outros autores podem estar relacionadas aos kits comerciais, à aparelhagem usada para as dosagens, ao método de colheita de amostras e da obtenção do soro. 
Ressalta-se que fatores relacionados ao clima, ao tipo de alimentação e ao manejo podem refletir nos resultados das análises, impossibilitando o uso de valores determinados em outros países como referência. Por essa razão, é importante a determinação dos parâmetros bioquímicos nas diferentes condições brasileiras.

Houve um decréscimo de aproximadamente 60,82 e $53,74 \%$ nos níveis de COL sérico das aves que receberam os tratamentos $\mathrm{FE}+\mathrm{FP}$ e FP em relação aquelas alimentadas com a dieta controle. De acordo com Borsa et al. (2011) os triglicerídeos e colesterol são componentes analisados nos testes de avaliação do metabolismo lipídico, sendo o triglicerídeo o lipídeo padrão do organismo, que constitui, em média, $95 \%$ de toda a gordura que existe no corpo. O colesterol é constituinte fundamental na estrutura das membranas celulares, síntese de ácidos biliares e hormônios esteroides. Entretanto, níveis séricos elevados de colesterol estão associados a problemas cardíacos em animais e humanos, portanto, a redução desta substância no organismo torna-se desejada.

Alguns estudos demonstram que a inclusão de aditivos como probióticos (KANASHIRO et al., 2001), minerais (MORAIS et al., 2001), ácidos graxos (RABER et al., 2008) e outras tecnologias podem alterar a concentração sérica de colesterol nas aves. Com os resultados obtidos pode-se inferir que os fatores $\mathrm{FE}+\mathrm{FP}$ e FP alteram o metabolismo de lipídeos das aves fazendo com que a fração de colesterol sérico seja diminuída. Entretanto, novos estudos devem ser realizados para compreender $\mathrm{o}$ mecanismo de atuação destes fatores no metabolismo lipídico dos frangos.

De uma maneira geral é possível inferir que a adição dos fatores homeopáticos na ração não afeta o desempenho dos frangos de corte aos 42 dias de idade, entretanto, melhoram rendimento de carcaça, o índice de eficiência produtiva, viabilidade e diminui o teor de colesterol sanguíneo.

\section{AGRADECIMENTOS \\ À Arenales, Homeopatia Animal pelo fornecimento dos produtos homeopáticos.}

\section{REFERÊNCIAS}

AMARAL, M.T.C.G. Homeopatia veterinária: estratégias de ação. Revista Cultura Homeopática, v.6, p.8-11, 2004.

ARENALES, M.C. Produção orgânica de aves de postura e corte. Revista Agroecologia Hoje, v.3, n.18, p.11-13, 2003.

BORATTO, A.J.; LOPES, D.C.; OLIVEIRA, R.F.M.; ALBINO, L.F.T.; SÁ, L.M.; OLIVEIRA, G.A. Uso de antibiótico, de probiótico e de homeopatia, em frangos de corte criados em diferentes ambientes térmicos, inoculados ou não com Escherichia coli. Revista Brasileira de Zootecnia, v.33, n.6, p.1477-1485, 2004.

BORSA, A.; KOHAYAGAWA, A.; BORETTI, L.P.; SAITO, M.E.; KUIBIDA, K. Níveis séricos de enzimas de função hepática em frangos de corte de criação industrial clinicamente saudáveis. Arquivos Brasileiros de Medicina Veterinária e Zootecnia, v.58, n.4, p.675-677, 2006.

BORSA, A.; KOHAYAGAWA A.; BORETTI, L.P.; SAITO, M.E. Efeitos da interação entre aflatoxicoses e doença infecciosa bursal sobre níveis de 
Rev. Bras. Saúde Prod. Anim., Salvador, v.15, n.2, p.394-405 abr./jun., 2014 http://www.rbspa.ufba.br ISSN 15199940

enzimas de função hepática, colesterol e triglicerídeos em frangos de corte.

Veterinária em Foco, v.8, n.2, p.132142, 2011.

BRIONES, S.F. Ensayos en pollos "broiler". Estudios sobre la Aplicación de Homeopatía en Producción Animal. Santiago de Chile, 1987. Disponível em: $<$ http:www.homeovet.cl/>. Acesso em: 5 dez. 2013.

CHABEL, J.C.; Van ONSELEN, V.J.; MORAIS, M.G.; NETO, I.M.C.; TEDESCHI, B.P. Efeito de um complexo homeopático "Homeobase Convert $\mathrm{H} 囚$ ®” em ovinos sob condições de restrição alimentar.

Brazilian Journal Veterinarian Research Animal Science, v.46, n.5, p.412-423, 2009.

CHAVES, T.C.B.; BERNARDO, A.R.; SANAVRIA, A.; BRITO, M. de F.; CRUZ, G. B. da; DANELLI, M.G.M.; MAZUR, C. Ineficiência da Thuja occidentalis no tratamento dos poxvirus aviários. Ciência Rural, v.36, n.4, p.1334-1336, 2006.

HADIPOUR, M.M.; HABIBI, G.H.; GHORASHINEJAD, A.; OLAYAIE, A.; TORKI, M. Evaluation of the homepathic remedies medication on comercial broiler chickens performance.

Journal of animal and veterinary advances, v.10, n.16, p.2102-1015, 2011.

KANASHIRO, A.M.I.; BOTTINO, J.A.; FERREIRA, F.; CASTRO, A.G.M. de; FERREIRA, A.J. P. Influência da administração contínua de probiótico a frangos de corte sobre atividades enzimáticas séricas e concentração de colesterol sérico. Arquivos do Instituto Biológico, v.68, n.2, p.11-17, 2001.
LABTEST. Disponível em: $<$ www.labtest.com.br $>$. Acesso em: 20 abr.2013.

LEITE, P.R.S.C.; MENDES, F.R.; PEREIRA, M.L.R.; LIMA, H.J.A.; LACERDA, M.J.R. Aditivos fitogênicos em rações de frangos. Enciclopédia Biosfera, v.8, n.15, p.926, 2012.

MINAFRA, C.S.; MORAES, G.H.K. de; RODRIGUES, A.C.P.; SILVA, F.A. da; STRINGHINI, J.H.; REZENDE, C.S.M.E. Perfil bioquímico e nutricional do ácido glutâmico e da vitamina $\mathrm{K}$ no soro e no fígado de frangos de corte de 1 a 21 dias de idade. Revista Brasileira de Zootecnia, v.37, n.11, p.1973-1977, 2008 .

MORAIS, S.C.D. de; MENTEN, J.F.M.; BRAINER, M.M. de A.; VALE, M.M. do. Altos níveis dietéticos de cobre no desempenho e no colesterol sérico e muscular de frangos de corte. Scientia Agricola, v.58, n.1, p.1-5, 2001.

MORO, D.N.; ZANELLA, I.; FIGUEIREDO, E.A.P.; SILVA, J.H.S.; Desempenho produtivo de quatro linhagens de frangos de corte. Ciência Rural, v.35, n.2, p.446-449, 2005.

OBA, A.; LONNI, A.A.S.G.; GUIMARÃES, I.G.; WAINE, J.; DUARTE, J.C.; MUNHOZ, V.M. Homeopatia para o tratamento de estresse de aves de reposição. In: CONGRESSO DE FARMÁCIA DE MARINGÁ, 1 ., 2006, Maringá. Anais...

Maringá:Universidade Estadual de Maringá; 2006. p.84.

RABER, M.R.; RIBEIRO, A.M.L.; KESSLER, A.M.; ARNAIZ, V.; LABRES, R.V. Desempenho, metabolismo e níveis plasmáticos de colesterol e triglicerídeos em frangos de 
Rev. Bras. Saúde Prod. Anim., Salvador, v.15, n.2, p.394-405 abr./jun., 2014 http://www.rbspa.ufba.br ISSN 15199940

corte alimentados com óleo ácido e óleo de soja. Ciência Rural, v.38, n.6, p.17301736, 2008

RIBEIRO, J.S.; GONÇALVES, T.M.; MACHADO, O.R.; CAMPOS, F.R.; FARIA, W.L. Homeopatia na terminação de novilhos nelores e tabapuãs confinados. Agropecuária Científica no Semi-Árido, v.7, n.1, p.38-44, 2011.

SIENA, E.C.; NATALI, M.R.M.; BRACCINI, G.L.; OLIVEIRA,A.C.; RIBEIRO, R.P.; VARGAS, L. Efeito do núcleo homeopático Homeopatila $100^{\circledR}$ na eficiência produtiva de alevinos revertidos de Tilápia do Nilo

(oreochromis niloticus). Semina:

Ciências Agrárias, v.31, n.4, p.985994, 2010.

TEIXEIRA, P.P.M.; SILVA, A.S.L.; VICENTE, W.R.R.; Castração na produção de ovinos e caprinos. Revista Científica Eletrônica de Medicina Veterinária, v.8, n.14, 2010.

Disponível em

$<$ http://www.revista.inf.br/veterinaria/ar tigos/RCEMV $>$. Acesso em: $10 \mathrm{dez}$.

2013.

TOLEDO, G.S.P.; COSTA, P.T.C.; SILVA, L.P.; PINTO, D.; FERREIRA, P.; POLETTO, C.J. Desempenho de frangos de corte alimentados com dietas contendo antibiótico e/ou fitoterápico como promotores, adicionados isoladamente ou associados. Ciência Rural, v.37, n.6, p.1760-1764, 2007.
UNIVERSIDADE FEDERAL DE VIÇOSA - UFV. SAEG 9.1: Sistema de Análises Estatística. Viçosa, MG: Fundação Arthur Bernardes, 2007.

VIEITES, F.M; MORAES, G.H.K; ALBINO, L.F.T. ROSTAGNO, H.S.; RODRIGUES, A.C; SILVA, F.A.; ATENCIO, A. Balanço eletrolítico e níveis de proteína bruta sobre o desempenho de pintos de corte de 1 a 21 dias de idade. Revista Brasileira de Zootecnia, v.33, p.2076-2085, 2004. Supl. 2.

VIZANNI, A.; NOVELLI, A. The effect of using homoeopathic remedies as growth promoting in poultry, 1992. In: OMEOMED FIRST INTERNATIONAL CONGRESS, 1992, Italy. Proceedings.... Ilaly: Istituto Superiore di Medicina Olistica e di Ecologia, 1993. p.175-178.

Data de recebimento: $13 / 01 / 2014$

Data de aprovação: 17/06/2014 